\title{
Cutis verticis gyrata secondary to cerebriform intradermal nevus
}

\author{
Olcay Er¹, Seray Külcü Çakmak', Serra Kayaçetin², Emine Tamer¹, Ferda Artüz \\ ${ }^{1}$ Dermatology Clinic, Ankara Numune Education and Research Hospital, Ankara, Turkey, ${ }^{2}$ Pathology Clinic, Ankara Numune \\ Education and Research Hospital, Ankara, Turkey
}

Corresponding author: Dr. Olcay Er, E-mail: olcayer88@gmail.com

\begin{abstract}
Cutis vertisis gyrata is a rare skin disease characterized with convoluted folds and furrows formed from thickened skin of the scalp. There are primary and secondary forms of the disease. We report a 22-years-old male patient with cutis verticis gyrata associated with cerebriform intradermal nevus which represents a rare secondary form of the disease.
\end{abstract}

Key words: Cutis verticis gyrata; Secondary; Cerebriform intradermal nevus

\section{INTRODUCTION}

Cutis verticis gyrata is a rare disease, characterized by skin folds and grooves resembling the brain surface [1]. It is usually observed on the scalp but involvement of neck, legs, buttocks and scrotum have also been reported [2]. Basically, it has been classified as primary (essential and non-essential) and secondary cutis verticis gyrata. The primary essential form evolves from normal skin, on the other hand secondary forms can be associated with neoplasms, inflammatory diseases, systemic and congenital diseases [3]. Cutis verticis gyrata associated with cerebriform intradermal nevi is among the rare secondary forms. In this case report we present a case of cutis verticis gyrate secondary to intradermal nevus.

\section{CASE REPORT}

A 22-years-old healthy man was admitted to our clinic with complaints of curved areas of the scalp that he had noticed 4 years ago. There was no history of trauma and there was no similar complaints in the family. Physical examination revealed slightly hyperpigmented soft and deep folds in the right temporal region and occipital regions of the scalp, in an area of about $9 \times 5 \mathrm{~cm}$ (Fig. 1). The lesions were asymptomatic with palpation. The nails and mucous membranes were normal. The examination of the neurological and ocular systems were normal. A skin biopsy was performed and the specimen was stained with hematoxylin and eosin (Fig. 2 and 3). Histopathological evaluation revealed intradermal nevi composed of nevus cells in the dermis in full thickness slot (Fig. 2). There was no cellular atypia. Solitary or clusters of nevus cells containing varying amounts of melanin in the dermis without a junctional component (Fig. 3). As a result of these symptoms the patient was diagnosed as cutis verticis gyrata secondary to intradermal nevus. The patient was referred to Plastic Surgery Clinic for total excision of the lesion.

Prior to the study, patient gave written consent to the examination and biopsy after having been informed about the procedure.

\section{DISCUSSION}

Cutis verticis gyrata; also known as pachyderma verticis girate, cutis verticis plicata and "bulldog" scalp syndrome was first described in 1837 by JeanLouis-Marc Albert. The term cutis verticis gyratqa was first used in 1907 by Unna [4]. In 1953 Polana Butterworth was grouped cutis verticis gyrata in two groups as primary and secondary forms. The primary form is divided into two as essential and

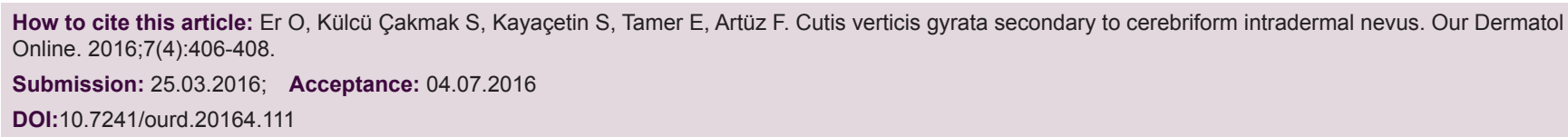




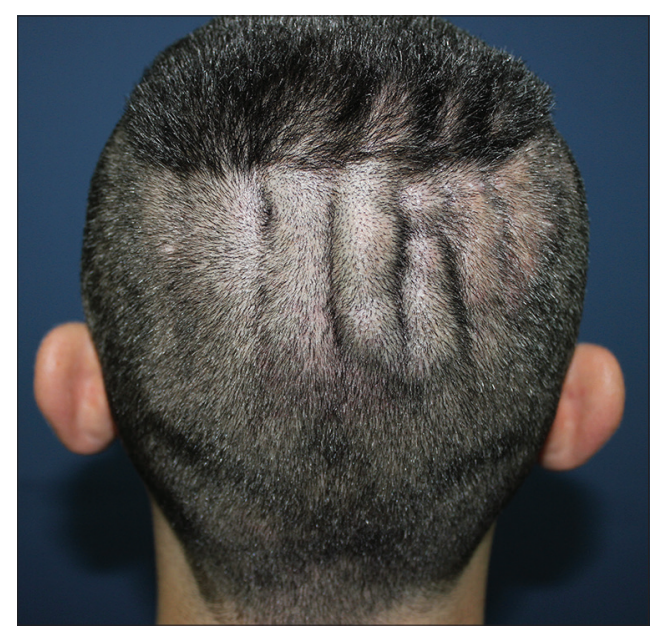

Figure 1: The deep folds extending in the right temporal and occipital region.

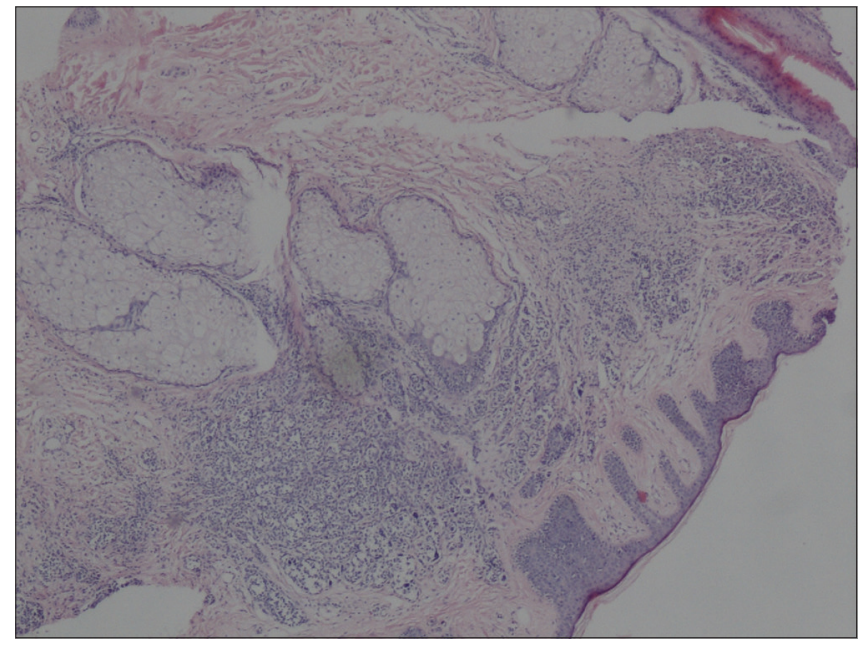

Figure 2: The nevus cell nests in all the dermis layers. (HEx40).

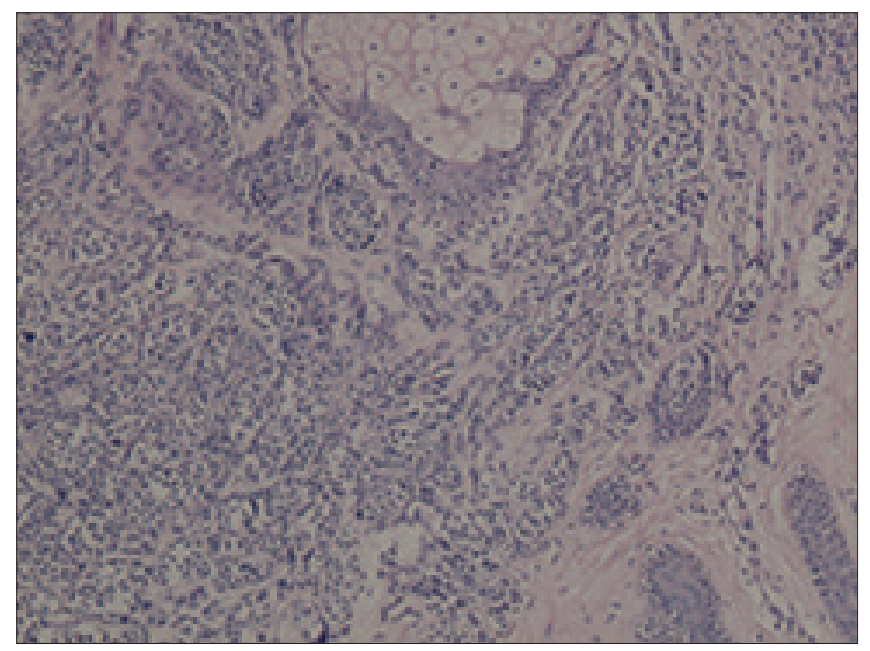

Figure 3: The nevus cell nests (HEX100).

non-essential. The primary essential form is mostly seen in men and the onset of the disease is during or after puberty [5]. It is not associated with any comorbidities. On the other hand the primary nonessential form is related with many neurological (microcephaly, mental retardation, cerebral palsy, epilepsy) or ophthalmologic (cataract, strabismus, blindness, retinitis pigmentosa) disorders [6].

The secondary form can be related with many disorders such as osteoarticular diseases (pachydermoperiostosis, acromegaly) that cause changes in the structure of the scalp, pituitary tumors, intracerebral aneurysm, amyloidosis, hypothyroidism, dermatofibroma, acanthosis nigricans, acne conglobata, cerebriform intradermal nevi, mucinosis, syphilis and diabetes mellitus type 2 . Furthermore it may be associated with various syndromes such as Noonan syndrome, Beare-Stevenson syndrome, Ehlers-Danlos Syndrome, "Michelin tire baby" syndrome, Turner syndrome and fragile X syndrome [7].

Cerebriform intradermal nevus is a variant of congenital melanocytic nevus growing on the scalp. It usually occurs at birth or in the first year of life and it is more common in women [8-10]. The mechanism of the cerebriform appearance of the cerebriform intradermal nevi is not clear. It is thought to be due to changes in epidermis or multifocal hyperplasia of nevus cells [9]. It is usually seen as an assymetrical skin coloured or slightly pigmented tumor, usually localized on the parietal and occipital regions of scalp. It usually gradually expands over the years. The size may vary from 2 to $25 \mathrm{~cm}$, sometimes even half or three quarters of the scalp can be affected [9]. There may be itching, tenderness, burning, recurrent infections, bleeding or musty smell [8]. The diagnosis is made by histopathological examination by observing nevus cells in the dermis. Nevus cells are well-defined slots or may be irregular and neuroid transformation may be present. The hair follicles may be normal or atrophic. Cerebriform intradermal nevus has potential for malignant melanoma transformation with a ratio of 4 to $5 \%$ [10]. Early diagnosis and surgical excision of the lesion is recommended because of malignant melanoma transformation risk and social, psychological repercussions of the disease.

In our case, a biopsy was taken from the lesion to exclude secondary causes and histopathological exmination was consistent intradermal nevus. The patient was referred to Plastic Surgery Clinic for the total excision of the lesion. It is important to recognize cutis verticis gyrate cases and to investigate the etiology. Cutis verticis gyrata secondary to cerebriform intradermal nevus has rarely been reported in the literature and the diagnosis should not be missed because of the risk of developing melanoma [10]. Our aim 
in this case report is to create awareness and provide ease of diagnosis to clinicians about cerebriform intradermal nevus and cutis verticis gyrata.

\section{Consent}

The examination of the patient was conducted according to the Declaration of Helsinki principles.

\section{REFERENCES}

1. Alcántara González J, Truchuelo Díez MT, Carrillo Gijón R, Martín Diaz RM, Jaén Olasolo P. Cerebriform intradermal nevus presenting as secondary cutis verticis gyrata. Dermatol Online J. 2010;16:14.

2. Quaedvlieg PJ, Frank J, Vermeulen AH, Toonstra J, van Neer FJ. Giant ceribriform intradermal nevus on the back of a newborn. Pediatr Dermatol. 2008;25:43-6.

3. Chagn GY. Cutis verticis gyrata, underrecognized neurocutaneous syndrome. Neurol. 1996;47:573-5.
4. Polan S, Butterworth T. Cutis verticis gyrata. A review with report of seven new cases. Am J Ment Retard. 1953;57:613-31.

5. Lasser AE. Cerebriform intradermal nevus. Pediatr Dermatol. 1983;1:42-4.

6. Diven DG, Tanus T, Raimer SS. Cutis Verticis Gyrata. Int J Dermatol. 1991;30:710-2.

7. Larsen F, Birchall N. Cutis verticis gyrata: Three cases with different aetiologies that demonstrate the classification system. Australas J Dermatol. 2007;48:91-4.

8. Yazıcı AC, İkizoğlu G, Baz K, Polat A, Üstünsoy D. Serbriform intradermal nevüs. Pediatr Dermatol. 2007;24:141-3.

9. Tabata H, Yamakage A, Yamazaki S. serebriform intradermal nevus. Int J Dermatol. 1995;34:634.

10. Hayashi Y, Tanioka M, Taki R, Sawabe K, Kore-eda S, Utani A, et al. Malignant melanoma derived from cerebriform intradermal naevus. Clin Exp Dermatol. 2009;34:e840-2.

Copyright by Olcay Er, et al. This is an open access article distributed under the terms of the Creative Commons Attribution License, which permits unrestricted use, distribution, and reproduction in any medium, provided the original author and source are credited.

Source of Support: Nil, Conflict of Interest: None declared. 